\title{
Effect of the ultrasound-Fenton oxidation process with the addition of a chelating agent on the removal of petroleum-based contaminants from soil
}

\author{
Ying $\mathrm{Li}^{1} \cdot$ Fangmin $\mathrm{Li}^{1}(\mathrm{D}) \cdot$ Fanxiu $\mathrm{Li}^{2} \cdot$ Fuqian Yuan ${ }^{1} \cdot$ Pingfang $\mathrm{Wei}^{2}$
}

Received: 3 June 2015 / Accepted: 30 July 2015 /Published online: 14 August 2015

(C) The Author(s) 2015. This article is published with open access at Springerlink.com

\begin{abstract}
The effects of ultrasonic irradiation, the chelating agent modified Fenton reaction, and a combination of ultrasound and the Fenton method in removing petroleum contaminants from a soil were studied. The results showed that the contaminant removal rate of the Fenton treatment combined with an oxalic acid chelating agent was $55.6 \%$ higher than that without a chelating agent. The average removal rate of the contaminants using the ultrasound-Fenton treatment was $59.0 \%$ higher than that without ultrasonic treatment. A combination of ultrasound and an $\mathrm{Fe}^{2+} / \mathrm{Fe}^{3+}$-oxalate complex-modified Fenton reagent resulted in significantly higher removal rates of $n$-alkanes $\left(\mathrm{C}_{\mathrm{n}} \mathrm{H}_{2 \mathrm{n}+2}, n<28\right)$, isoprenoid hydrocarbons, aromatic hydrocarbons, and saturated polycyclic terpenes compared with the ultrasound treatment alone or the Fenton method. The Fenton reaction and the ultrasound-Fenton treatment can unselectively remove multiple components of residual hydrocarbons and a number of benzene rings in polycyclic aromatic hydrocarbons. The chemistry of the heterocyclic compounds and the position and number of substituents can affect the degradation process.
\end{abstract}

Responsible editor: Zhihong Xu

Fangmin Li

lifangmin@yeah.net

Ying Li

li_xiaomie@126.com

1 School of Chemistry and Environmental Engineering, Yangtze University, Jingzhou 434023, People's Republic of China

2 Branch Laboratory of Yangtze University, Health Safety and Environment (HSE) Key Laboratory of PetroChina Company Limited, Jingzhou 434023, People's Republic of China
Keywords Fenton reaction · Ultrasound · Petroleum hydrocarbons $\cdot$ Removal rate $\cdot$ Oxidation

\section{Introduction}

Crude oil spills, oily wastewater, and oily mud resulting from oil exploration, drilling, refining, and transportation can cause serious soil contamination (Tsai and Kao 2009). After entry into the soil, petroleum hydrocarbons move outward with rain and downward into the surrounding soil, contaminating surface water and groundwater and reducing or stopping plant growth. Oil contamination can also affect human health through the food chain (Al-Mutairi et al. 2008; Mater et al. 2006). For example, polycyclic aromatic carbohydrate residues in soil and crop seeds are toxic, and their degradation rates are very slow under natural conditions.

The Fenton oxidation process produces hydroxyl radicals with strong oxidizing power by $\mathrm{Fe}^{2+}$-catalyzed decomposition of hydrogen peroxide under acidic conditions. It is widely used in the degradation of organic pollutants (Pignatello et al. 2006). The conventional Fenton reaction requires a low $\mathrm{pH}$ value $(\mathrm{pH}<3.0)$ to prevent the precipitation of iron oxyhydroxides (Watts and Teel 2005), but the natural $\mathrm{pH}$ values of many soil types are near neutral or are slightly alkaline. If the $\mathrm{pH}$ of soil was adjusted to an acidic value (less than 3.0 ), the remediation of polluted soil will increase the processing cost and destroy the natural environment of the soil, resulting in a serious ecological problem. These types of problems are solved by using chelating agents. The solubility of iron ions $\left(\mathrm{Fe}^{2+}\right.$ or $\left.\mathrm{Fe}^{3+}\right)$ can be increased significantly, and the precipitation of the iron ion can be prevented with the use of chelating agents. Therefore, the removal rates of organic contaminants increase considerably under Fenton oxidation and in Fenton-like systems ( $\mathrm{Lu}$ et al. 2010a; Vicente et al. 2011; 
Watts and Teel 2005). Xue et al. (2009) reported that the oxidation efficiencies of pentachlorophenol were improved significantly by using six kinds of chelating agents (ethylenediaminetetraacetic acid (EDTA), oxalate, carboxymethyl- $\beta$ cyclodextrin (CMCD), tartrate, citrate, and succinate) in a Fenton system at neutral $\mathrm{pH}$. The removal rate of pentachlorophenol with oxalate was higher than that obtained using five other kinds of chelating agents in a heterogeneous Fenton-like reaction catalyzed by $\mathrm{Fe}_{3} \mathrm{O}_{4}$ (Xue et al. 2009). Consequently, the iron-chelating compounds can maintain a relatively high concentration of iron in solution and increase the removal rate, even if outside the ideal operating $\mathrm{pH}$ range for Fenton's reagent. Chelating iron oxidation systems have increased the operating range of the conventional Fenton system to $\mathrm{pH}$ of 6.0-8.5 (Lu et al. 2010b; Watts and Teel 2005). Therefore, the modified Fenton reaction system can be applied directly to environmental conditions in a neutral $\mathrm{pH}$ range.

Oxalate is a kind of environmentally friendly and nontoxic chelating agent that easily forms an organic ligand with $\mathrm{Fe}^{2+}$ or $\mathrm{Fe}^{3+}$. It also has the advantages of high activity of the iron ion in solution and a low scavenging effect on the hydroxyl radical in the Fenton reaction (Xue et al. 2009; Venny et al. 2012b). Therefore, it is regarded as a chelating agent with good developmental prospects for the Fenton reaction to remediate organic polluted soil with a natural soil $\mathrm{pH}$.

Many studies have demonstrated that the $\mathrm{Fe}^{2+}$-catalyzed Fenton reaction and the $\mathrm{Fe}^{3+}$-catalyzed Fenton-like reaction can effectively degrade many organic pollutants in water and soil (Bokare and Choi 2014; Jiang et al. 2013; Venny et al. 2012a, b). However, these types of oxidation reactions can only occur in aqueous solutions. The organic pollutants in soil can only be oxidized when they are desorbed from the soil particles. Ultrasound and other physical methods can improve the rate of desorption of organic contaminants in soil and increase the corresponding degradation rate (Ning et al. 2014; Souza et al. 2014; Chakma and Moholkar 2011). A combination of ultrasound and the Fenton oxidation method can improve the removal rate of organic pollutants from sewage and soil (ElShafei et al. 2014; Ning et al. 2014; Siddique et al. 2014). To degrade nitrobenzene in water, ElShafei et al. (2014) used nanoscale $\alpha-\mathrm{Fe}_{2} \mathrm{O}_{3}$ and $\mathrm{CuO}$ to produce an ultrasound-assisted Fenton-like reaction under neutral $\mathrm{pH}$ conditions, in which the first-order reaction rate constant in the degradation kinetic equation was $60 \%$ greater than that obtained using only the ultrasonic treatment. Nitrobenzene was completely degraded after 10-min ultrasonication in the $\alpha-\mathrm{Fe}_{2} \mathrm{O}_{3}$-catalyzed Fenton reaction and after 25-min ultrasonication in a $\mathrm{CuO}$-catalyzed Fenton reaction. Zhang et al. (2013) studied the effects of ultrasound, the Fenton reaction, and a combination of ultrasound and the Fenton reaction on the removal of total petroleum hydrocarbons
(TPHs) from oil sludge. The TPH removal rates using the above three types of advanced oxidation processing (AOP) methods were $22.6,13.8$, and $43.1 \%$, respectively, suggesting that there was a combined effect resulting from the use of the ultrasonic treatment and the Fenton method.

In this paper, we evaluated the effect of AOPs, including ultrasonication, the modified Fenton reaction with a chelating agent, and an ultrasound-Fenton combination reaction, on the removal of petroleum contaminants from soil, and analyzed the components of residual petroleum hydrocarbons after these treatments using gas chromatography-mass spectrometry (GC-MS).

\section{Materials and methods}

\section{Petroleum-contaminated soil sample}

In order to reduce the effects of soil organic matter and carbonate on the Fenton oxidant, a yellow-brown clay loam soil without petroleum contaminants was collected from the Huangshan village of Jingzhou City $\left(30^{\circ} 24^{\prime}\right.$ $\left.23.93^{\prime \prime} \mathrm{E}, 112^{\circ} 11^{\prime} 28.77^{\prime \prime} \mathrm{N}\right)$, which was selected as the experimental soil; this soil had a low organic matter and was collected from the $40-70-\mathrm{cm}$ soil horizon. The soil sample was air-dried and ground to pass through a 1.43mm-mesh sieve. The soil $\mathrm{pH}$ was 5.9 , the organic matter content was $6.78 \mathrm{~g} / \mathrm{kg}$ (determined by the method of potassium bichromate oxidimetry), and the effective iron content (determined by using diethylene-triamine-pentaacetic acid (DTPA) extraction-atomic absorption spectrometry) was $17.95 \mathrm{mg} / \mathrm{kg}$. The designed petroleum contaminant concentration in the spiked soil was $25 \mathrm{~g} / \mathrm{kg}$. Crude oil was heated in a water bath at $50{ }^{\circ} \mathrm{C}$, and $25.00 \mathrm{~g}$ of a well-mixed oil sample was weighed and placed in a beaker. The sample was fully dissolved with $n$-hexane and acetone (volume ratio of 1:1) and then evenly mixed with $975.00 \mathrm{~g}$ of soil. Subsequently, the samples were thoroughly mixed at $150 \mathrm{rpm}$ for $2 \mathrm{~h}$ and allowed to stand in a fume hood for 4 weeks until the solvent in the samples had completely evaporated and the samples were ready for use.

\section{Experimental design}

The experimental design and the treatments are listed in Table 1. The ratio of soil to water was $5 \mathrm{~g}: 30 \mathrm{~mL}$; all experiments were performed in triplicates. The petroleum-contaminated soil samples were treated as follows: $2 \mathrm{~mL}$ of $20 \%$ sodium sulfite was added $72 \mathrm{~h}$ after the reaction had started to stop the oxidation (Goi et al. 2006). 
Table 1 The experimental design and treatment

\begin{tabular}{lllll}
\hline Run & Ultrasonic & Chelating agent $/ \mathrm{mol} \mathrm{L}^{-1}$ & Catalyst/mol L & Oxidant/mol L \\
\hline I & - & - & - & - \\
III & - & - & $\mathrm{FeSO}_{4}(20)$ & $\mathrm{H}_{2} \mathrm{O}_{2}(1000)$ \\
V & - & Oxalic acid (20) & $\mathrm{FeSO}_{4}(20)$ & $\mathrm{H}_{2} \mathrm{O}_{2}(1000)$ \\
VII & - & Oxalic acid (60) & $\mathrm{Fe}_{2}\left(\mathrm{SO}_{4}\right)_{3}(20)$ & $\mathrm{H}_{2} \mathrm{O}_{2}(1000)$ \\
II & $75 \mathrm{~W}$ & - & - & - \\
IV & $20 \mathrm{kHz}$ & - & $\mathrm{FeSO}_{4}(20)$ & $\mathrm{H}_{2} \mathrm{O}_{2}(1000)$ \\
VI & $30 \mathrm{~min}$ & Oxalic acid (20) & $\mathrm{FeSO}_{4}(20)$ & $\mathrm{H}_{2} \mathrm{O}_{2}(1000)$ \\
VIII & & Oxalic acid (60) & $\mathrm{Fe}_{2}\left(\mathrm{SO}_{4}\right)_{3}(20)$ & $\mathrm{H}_{2} \mathrm{O}_{2}(1000)$ \\
\hline
\end{tabular}

\section{Measurement}

\section{Extraction of petroleum residues from soil}

After a 72-h treatment, the soil slurry was transferred to a centrifuge tube to separate the liquid and solid phases by running $10 \mathrm{~min}$ at $6500 \mathrm{rpm} / \mathrm{min}$. The petroleum residues in the liquid and solid phases were extracted with dichloromethane. The liquid phase sample was extracted in a separatory funnel with a Teflon stopcock, and the solid phase sample was extracted using a Soxhlet extractor for $8 \mathrm{~h}$ (Lu et al. 2010a, b). Subsequently, the liquid and solid phase extracts were combined and concentrated to a volume of $3 \mathrm{~mL}$ in a rotary evaporator at $54{ }^{\circ} \mathrm{C}$. The sample was then transferred to a short glass column with a bottom layer of cotton and a top layer of anhydrous sodium sulfate for dehydration, and the eluent was collected in a $25-\mathrm{mL}$ beaker. The solvent was evaporated under a fume hood, and the sample was dried to a constant weight in a vacuum oven at $40{ }^{\circ} \mathrm{C}$ (Villalobos et al. 2008).

The asphaltenes in the petroleum residues were precipitated with $n$-hexane $(60 \mathrm{~mL})$. Silica gel-alumina column chromatography was used to separate the asphaltene-free sample into saturated hydrocarbons, aromatic hydrocarbons, and nonhydrocarbons with the solvents of $n$-hexane, dichloromethane $+n$-hexane $(v / v=1: 1)$, and of ethanol + chloroform (each $10 \mathrm{~mL})$, respectively.

\section{Determination of saturated hydrocarbon components in the residual oil}

The standard $\mathrm{C}_{24} \mathrm{D}_{50}$ was added to $10 \mathrm{mg}$ of the saturated hydrocarbon samples to conduct the gas chromatography measurements with Shimadzu GC-14C (Shimadzu, Japan). The analytical conditions were as follows: Agilent HP-1 capillary column $(30 \mathrm{~m} \times 0.32 \mathrm{~mm} \times 0.25 \mu \mathrm{m})$ with carrier gas $\left(\mathrm{N}_{2}\right)$ flow rate of $2 \mathrm{~mL} / \mathrm{min}$, air flow rate of $300 \mathrm{~mL} / \mathrm{min}, \mathrm{H}_{2}$ flow rate of $30 \mathrm{~mL} / \mathrm{min}$, makeup gas flow rate of $28 \mathrm{~mL} / \mathrm{min}$, and injection volume of $1 \mu \mathrm{L}$. The temperature program was 1 -min isothermal heating at $70{ }^{\circ} \mathrm{C}$, and the oven temperature was increased to $100^{\circ} \mathrm{C}$ at a rate of $8{ }^{\circ} \mathrm{C} / \mathrm{min}$ (held for $2 \mathrm{~min}$ ) and then increased to $300{ }^{\circ} \mathrm{C}$ at a rate of $4{ }^{\circ} \mathrm{C} / \mathrm{min}$ and held for
$20 \mathrm{~min}$. The inlet temperature and the detector temperature were both $300{ }^{\circ} \mathrm{C}$.

Determination of biomarkers and aromatic components in the residual oil

The standards $5 \alpha$-androstane and anthracene- $\mathrm{D}_{10}$ were added to the samples of saturated hydrocarbons and aromatic hydrocarbons to conduct GC-MS measurements (Hewlett-Packard GC6890/5973MSD, Agilent, Santa Clara, CA). The column was HP-5MS $(60 \mathrm{~m} \times 0.25 \mathrm{~mm} \times 0.25 \mu \mathrm{m})$ with the $\left(\mathrm{N}_{2}\right)$ carrier gas flow rate of $2 \mathrm{~mL} / \mathrm{min}$. The temperature program was isothermal heating at $50{ }^{\circ} \mathrm{C}$ for $1 \mathrm{~min}$, followed by an oven temperature increase to $100{ }^{\circ} \mathrm{C}$ at $8^{\circ} \mathrm{C} / \mathrm{min}$, which was then increased to $310{ }^{\circ} \mathrm{C}$ at $4{ }^{\circ} \mathrm{C} / \mathrm{min}$ and held at this temperature for $22.5 \mathrm{~min}$. The following conditions were used: constant current mode with flow rate of $1.0 \mathrm{~mL} / \mathrm{min}$, inlet temperature of $290{ }^{\circ} \mathrm{C}$, MS ionization mode of EI, electron energy of $70 \mathrm{eV}$, and mass range of 50-450 amu.

\section{Data analysis}

The statistical analyses of the experimental data were performed using the Statistical Product and Service Solutions (SPSS) 18.0 software. The data used were the average values of three repeated experiments, and the differences were considered significant at $p<0.05$ and extremely significant at $p<0.01$.

\section{Results and discussion}

\section{Effects of ultrasound and Fenton treatment on the removal rate of residual oil}

The effects of the ultrasound, Fenton, and ultrasound-Fenton treatments on the removal of residual oil from the soil are shown in Fig. 1. Statistically significant differences in the removal rate were observed between the treatments $(p<0.01)$. The highest removal rate $(88.0 \%)$ was measured in treatment VIII, and the lowest was analyzed in the control 


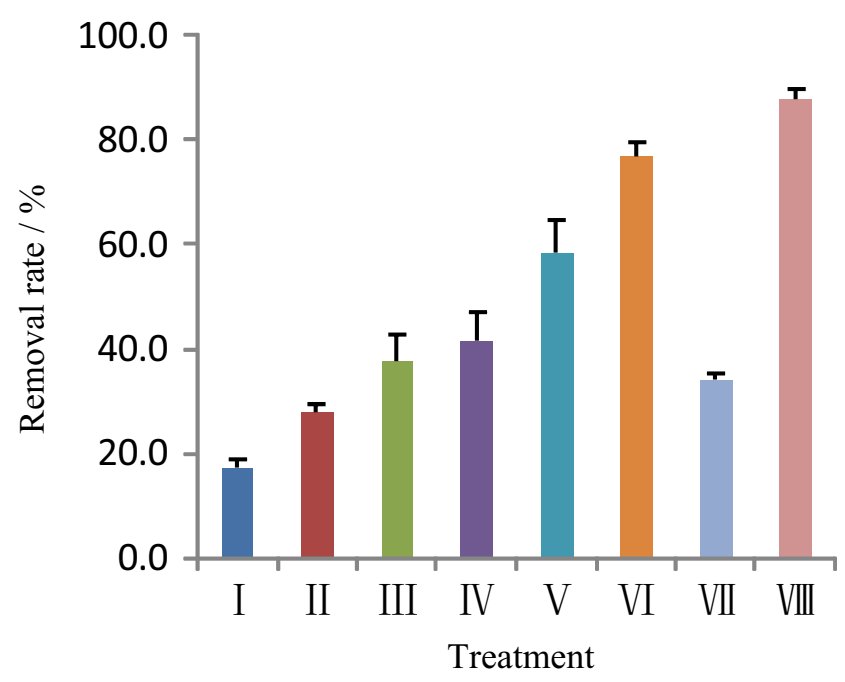

Fig. 1 Effect of each treatment on the removal rate of residual oil from the spiked soil

treatment $(17.4 \%)$. The average removal rate of the ultrasound-Fenton treatment was $59.0 \%$ higher than that of the Fenton treatment. The removal rate of treatment V, which contained the chelating agent oxalic acid, was $55.6 \%$ higher than that of treatment III without the chelating agent. The removal rate of the Fenton reaction was $116.1 \%$ higher than that of the control. The presence of ultrasound and the addition of the chelating agent oxalic acid, using either $\mathrm{Fe}^{3+}$ or $\mathrm{Fe}^{2+}$ as a catalyst, significantly improved the removal rate of the residual oil from the contaminated soil.

Degradation of organic pollutants using ultrasonic treatment results from the free radicals ${ }^{\circ} \mathrm{OH}, \mathrm{O}$, and $\mathrm{HO}_{2} \cdot$ that are produced from water molecules in the extreme microenvironment (high temperature and high pressure) (Sivasankar and Moholkar 2009; ElShafei et al. 2014). At the same time, highspeed micro-jets generated from cavitation can cause friction and dispersion of soil particles (Ning et al. 2014), causing the relatively insoluble petroleum molecules to be desorbed from the soil particle surfaces. Ultrasonic treatment can thus help to degrade the organic pollutants in the solid and liquid phases (Chakma and Moholkar 2011). However, the degradation rate with ultrasonication only is relatively low. A combination of ultrasonication with the Fenton reaction substantially improved the degradation of organic pollutants because the combination promoted the generation of hydroxyl radicals (Siddique et al. 2014; Ning et al. 2014). The level of hydroxyl radicals produced in the combined ultrasound-Fenton treatment was 10 times that of the ultrasonication treatment alone (Siddique et al. 2014). The use of ultrasound also promoted the conversion of $\mathrm{Fe}^{3+}$ to $\mathrm{Fe}^{2+}$ and accelerated the degree of organic contaminant mineralization. The ultrasound combined $\mathrm{Fe}^{3+}$-catalyzed Fenton-like oxidation treatment led to the direct elimination of volatile and low molecular weight organic products (Zhou et al. 2011). The results of the current experiment also showed that the removal rate of residual oil from the soil in the ultrasonic combined $\mathrm{Fe}^{3+}$-oxalate-catalyzed Fenton-like treatment (VIII) was $157.3 \%$ higher than that of the $\mathrm{Fe}^{3+}$-catalyzed Fenton-like treatment (without ultrasound; VII); the difference between treatments VIII and VII was extremely significant $(p<0.01)$.

In the traditional Fenton reaction, a low $\mathrm{pH}(<3.0)$ is necessary to prevent the catalyst iron ion from forming a precipitate as $\mathrm{Fe}(\mathrm{OH})_{3}$. However, when soil $\mathrm{pH}$ is neutral to slightly alkaline, water-soluble complexes will be formed by the addition of a chelating agent and iron ions $\left(\mathrm{Fe}^{2+}, \mathrm{Fe}^{3+}\right)$ and other transition metal ions. The oxalate ion $\left(\mathrm{C}_{2} \mathrm{O}_{4}{ }^{2-}\right)$ chelating agent has two oxygen atoms with unshared pairs of electrons, and in the presence of ferric $\left(\mathrm{Fe}^{3+}\right)$ and ferrous $\left(\mathrm{Fe}^{2+}\right)$ ions, oxalate ions can generate five-membered rings and form different complex ions to maintain a sufficient concentrations of iron ions in solution (Souza et al. 2014). This can promote the production of hydroxyl radicals by $\mathrm{H}_{2} \mathrm{O}_{2}$, improving the efficiencies of oxidation of organic pollutants (Venny et al. 2012b; Vicente et al. 2011; Rastogi et al. 2009). Lu et al. (2010a) used a modified Fenton's reagent (EDTA-Fe ${ }^{3+}+\mathrm{H}_{2} \mathrm{O}_{2}$ ) to remediate petroleumcontaminated soil at $\mathrm{pH} 7$, and the petroleum-related pollutants were significantly reduced from 14.8 to $2.3 \mathrm{~g} / \mathrm{kg}$. A compositing method used to mix citrate iron $\left(\mathrm{Fe}^{3+}\right)+\mathrm{H}_{2} \mathrm{O}_{2}(\mathrm{pH} \sim 7)$ with petroleum-contaminated soil also contributed to contaminant removal (Lu et al. 2010b).

The results from this experiment showed that the removal rate of petroleum contaminants in the Fenton combined with the $\mathrm{Fe}^{2+}$-oxalate complex treatment $(\mathrm{V})$ was $55.6 \%$ higher than that of the Fenton without the chelating agent treatment (III), but the removal rate of the Fenton combined with the $\mathrm{Fe}^{3+}$-oxalate complex treatment (VII) was $9.0 \%$ lower than that of the Fenton treatment (III). Since the reaction rate of the $\mathrm{Fe}^{3+}$-catalyzed Fenton-like reaction is slower than that of the conventional $\mathrm{Fe}^{2+}$-catalyzed Fenton reaction by at least 3 orders of magnitude (Pignatello et al. 2006; Venny et al. 2012b), the Fenton-like reaction requires ultraviolet (UV) radiation or ultrasonic (US) treatment to accelerate the reduction of $\mathrm{Fe}^{3+}$ to $\mathrm{Fe}^{2+}$ (Zhou et al. 2011; Bokare and Choi 2014). Without $\mathrm{UV}$ radiation, the conversion of $\mathrm{Fe}^{3+}$ to $\mathrm{Fe}^{2+}$ is affected to a certain degree, and the removal rate of organic contaminants in the Fenton-like reaction is very low (Souza et al. 2014). In the absence of ultrasonic irradiation, the removal rate of the residual oil from soil was very low (only $34.2 \%$ ) in the $\mathrm{Fe}^{3+}$-catalyzed Fenton treatment with the addition of oxalic acid chelating agent (VII). In addition, oxalate and other chelating agents have high reaction rates with $\cdot \mathrm{OH}$ and can also act as $\cdot \mathrm{OH}$ scavengers (Zhou et al. 2011). Therefore, under no ultrasonic irradiation, a competitive relationship was formed between the petroleum contaminants and oxalate ligand in the reaction with $\mathrm{OH}$. This is one of the reasons that the removal rate of the residual oil in treatment VII was relatively low. 


\section{Effects of ultrasound and Fenton treatment on saturated hydrocarbon components}

\section{Normal alkanes (n-alkanes)}

Almost all concentrations of the $n$-alkanes $\left(\mathrm{C}_{15}-\mathrm{C}_{34}\right)$ in the Fenton, ultrasonic, and ultrasound-Fenton treatments were lower than those in the control (Fig. 2). The light $n$-alkane $\left(\mathrm{C}_{\mathrm{n}} \mathrm{H}_{2 \mathrm{n}+2}, n \leq 14\right)$ components appeared to have been volatilized in all treatments because their presence was undetected. The removal effects were significant for the ultrasound- $\mathrm{Fe}^{2+} / \mathrm{Fe}^{3+}$-oxalate complex treatments VI and VIII. The concentrations of the $n$-alkane components for both treatments were 69.8-99.3 and 81.6-99.9\% lower than the control concentrations, respectively. The removal rates of the $n$-alkenes $\left(\mathrm{C}_{\mathrm{n}} \mathrm{H}_{2 \mathrm{n}+2}, n<28\right)$ in the Fenton, ultrasound-Fenton, and Fenton treatments with the $\mathrm{Fe}^{2+}$-oxalate complex (treatments III, IV, and $\mathrm{V}$ ) were obvious, and the concentrations of the $n$-alkane components in the three treatments were 15.9-83.1, 22.8-64.4, and $32.0-79.0 \%$ lower than the control concentrations, respectively. The Fenton treatment with the $\mathrm{Fe}^{3+}$-oxalate complex (treatment VII) resulted in a significantly greater removal of compounds with carbon chains shorter than $\mathrm{C}_{25}$, and the concentrations of the $n$-alkane components were $-1.4-70.2 \%$ lower than that of the control. The removal effect of the ultrasound-only treatment was not significant. The values of $\sum \mathrm{nC}_{21} / / \sum \mathrm{nC}_{22+}$ of each treatment (Table 1) similarly reflect the differences in these treatments. The ultrasound-Fenton treatment was the best for removing the short-chain $n$-alkanes $\left(\leq \mathrm{C}_{21}\right)$ that often originate from aquatic algae and microorganisms, followed by the Fenton treatment, and the Fenton treatment with the addition of a chelating agent. The ultrasound-only treatment had weak removal capability.

\section{Isoprenoid hydrocarbons}

The removal capability of each treatment with respect to the isoprenoid hydrocarbons in the residual oil was ranked as

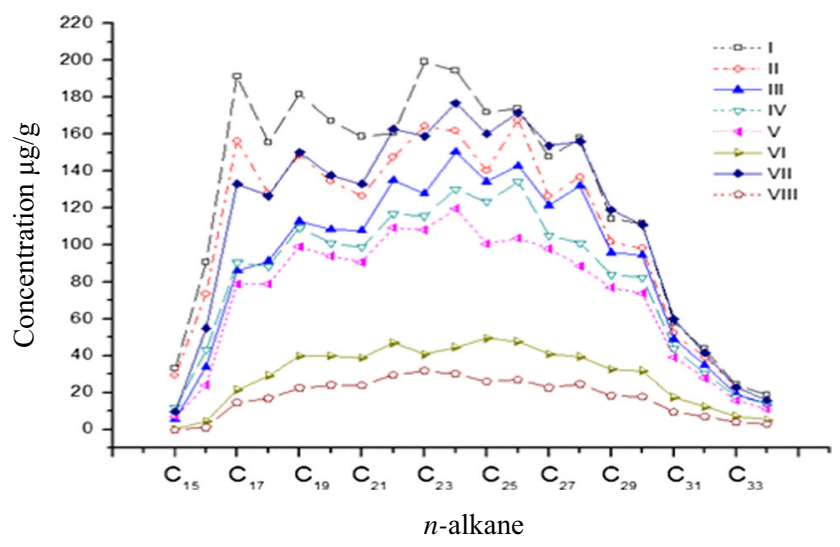

Fig. 2 Concentration distribution of $n$-alkane in residual oil of contaminated soil in each treatment follows: VIII $>$ VI $>$ V $>$ IV $>$ III $>$ VII $>$ II $>$ I (Table 2). This was consistent with the rankings of the removal rates of residual oil from soil. Among these, the removal rates of phytane $(\mathrm{Ph})$ and pristane $(\mathrm{Pr})$ in treatments VIII and VI were the highest, and their concentrations were 90.4-94.7 and 81.1$87.9 \%$ lower than that of the control, respectively. The removal rates of $\mathrm{Ph}$ and $\mathrm{Pr}$ in the III, IV, and V treatments were second highest, and their concentrations were 35.9-49.1, 38.7-50.8, and 52.0-60.5\% lower than that of the control, respectively. The removal rates of $\mathrm{Ph}$ and $\mathrm{Pr}$ in the II and VII treatments were relatively low, and their concentrations were only $17.0-19.6$ and $20.5-20.7 \%$ lower than that of the control, respectively. Similar removal effects on $\mathrm{C}_{16}-\mathrm{C}_{18}$ isoalkanes were found for each treatment. For parameters $\mathrm{Pr} /$ $\mathrm{nC}_{17}$ and $\mathrm{Ph} / \mathrm{nC}_{18}$, the values for treatment VIII were significantly lower than that of the control, but no significant differences were found between the other treatments and the control. Therefore, the ultrasound- $\mathrm{Fe}^{2+} / \mathrm{Fe}^{3+}$-oxalate complex treatment showed good removal of $\mathrm{Pr}$ and $\mathrm{Ph}$. The Fenton reaction or the ultrasound-Fenton reaction can provide effective and non-selective removal of a variety of petroleum hydrocarbon components.

\section{Saturated hydrocarbon biomarkers-terpenoids $(\mathrm{m} / \mathrm{z}=123$, 191)}

By using spectral characteristics of terpenoid biomarkers and the ion fragment information from mass spectrometry (MS), we determined the contents of 48 types of terpenes, including 9 bicyclic sesquiterpene compounds, 17 tricyclic terpanes, 1 tetracycline terpane, and 21 pentacyclic terpenes (hopanes).

The concentrations of the $\mathrm{C}_{14}, \mathrm{C}_{15}$, and $\mathrm{C}_{16}$ bicyclic sesquiterpenes were significantly reduced in the Fenton and ultrasound-Fenton treatments. The bicyclic terpenes were reduced to undetectable levels in treatment VIII. The concentration of terpenoids in the ultrasound-only treatment (II) was comparable to the control, while the concentrations in treatments III, IV, and VII were 57.8-77.0 \% lower than the control. The concentrations of bicyclic terpenes in treatments $\mathrm{V}$, VI, and VIII were 91.9-100\% lower than that of the control. The effects of each treatment on the tricyclic terpenes, tetracyclic terpenes, and pentacyclic terpenes followed the same order. Compared with the control, the concentrations of tricyclic terpenes, tetracyclic terpenes, and pentacyclic terpenes in treatments II, III, and VII were obviously reduced by 23.3-32.3\%; the same terpenoid concentrations in treatments IV and V were reduced highly significantly by $40.5-49.9 \%$; treatments VI and VIII provided extremely significant terpenoid removal and the concentrations were reduced by $76.7-$ $86.7 \%$ (Fig. 3). These results showed that ultrasonic treatment with the addition of the $\mathrm{Fe}^{2+}$ - or $\mathrm{Fe}^{3+}$-oxalate complex in the Fenton reaction effectively removed the terpenoid contaminants in residual oil, especially bicyclic terpenes. 
Table 2 Effects of experimental treatments on the parameters of isoprenoid hydrocarbons in residual oil

\begin{tabular}{|c|c|c|c|c|c|c|c|c|}
\hline \multirow[t]{2}{*}{ Parameters } & \multicolumn{8}{|c|}{ Treatments } \\
\hline & I & II & III & IV & V & VI & VII & VIII \\
\hline $\operatorname{Pr}(\mu \mathrm{g} / \mathrm{g})^{\mathrm{a}}$ & 159.20 & 132.11 & 81.05 & 78.39 & 62.89 & 19.24 & 126.26 & 8.37 \\
\hline $\mathrm{Ph}(\mu \mathrm{g} / \mathrm{g})^{\mathrm{b}}$ & 406.37 & 326.59 & 260.44 & 249.21 & 195.13 & 76.96 & 323.07 & 38.92 \\
\hline $\mathrm{Pr} / \mathrm{Ph}$ & 0.39 & 0.40 & 0.31 & 0.31 & 0.32 & 0.25 & 0.39 & 0.21 \\
\hline $\mathrm{Pr} / \mathrm{nC}_{17}{ }^{\mathrm{c}}$ & 0.85 & 0.85 & 0.94 & 0.87 & 0.80 & 0.89 & 0.94 & 0.56 \\
\hline $\mathrm{Ph} / \mathrm{nC}_{18}$ & 2.62 & 2.55 & 2.87 & 2.81 & 2.47 & 2.62 & 2.56 & 2.30 \\
\hline$\sum\left(\mathrm{iC}_{16}-\mathrm{iC}_{18}\right)^{\mathrm{d}}$ & 169.42 & 128.33 & 62.08 & 63.71 & 43.16 & 11.55 & 95.38 & 8.60 \\
\hline$\sum \mathrm{nC}_{21}-\sum \mathrm{nC}_{22+}{ }^{\mathrm{e}}$ & 0.62 & 0.58 & 0.44 & 0.50 & 0.49 & 0.42 & 0.50 & 0.41 \\
\hline \multicolumn{9}{|l|}{${ }^{\mathrm{a}} \mathrm{Pr}=$ pristine } \\
\hline \multicolumn{9}{|l|}{${ }^{\mathrm{b}} \mathrm{Ph}=$ phytane } \\
\hline \multicolumn{9}{|c|}{${ }^{\mathrm{c}} \mathrm{nC}_{17}=n$-alkane of $\mathrm{C}_{17}\left(\mathrm{C}_{17} \mathrm{H}_{36}\right)$} \\
\hline \multicolumn{9}{|c|}{${ }^{\mathrm{d}} \mathrm{iC}_{16}=$ isoalkane of $\mathrm{C}_{16}\left(\mathrm{C}_{16} \mathrm{H}_{34}\right)$} \\
\hline
\end{tabular}

\section{Saturated hydrocarbon biomarkers—steroids $(\mathrm{m} / \mathrm{z}=217)$}

The spectral characteristics of the steroid biomarkers and the ion fragment information from mass spectrometry indicated that there were 27 types of sterane compounds, including pregnane $\left(\mathrm{C}_{21}\right)$, homopregnane $\left(\mathrm{C}_{22}\right)$, regular steranes $\left(\mathrm{C}_{27}\right.$, $\left.\mathrm{C}_{28}, \mathrm{C}_{29}\right)$, and rearranged steranes $\left(\mathrm{C}_{27}, \mathrm{C}_{28}\right)$. The parameter characteristics of the saturated hydrocarbon biomarkers in residual oil are shown for each treatment from Table 3. The values such as pregnane index, the ratios of regular steranes and rearranged steranes, regular steranes and hopane, normoretane and moretane, and $\mathrm{T}_{\mathrm{m}}$ and $\mathrm{T}_{\mathrm{s}}$, etc. for the ultrasound-Fenton treatment (VI, VIII) were significantly lower than those of other treatments. These results indicated that in treatments providing the highest removal rate of saturated hydrocarbons, regular steranes and pregnane were more easily oxidized and decomposed compared with rearranged steranes and $\mathrm{C}_{29}$ regular steranes, and $\mathrm{T}_{\mathrm{m}}$ and normoretane were more

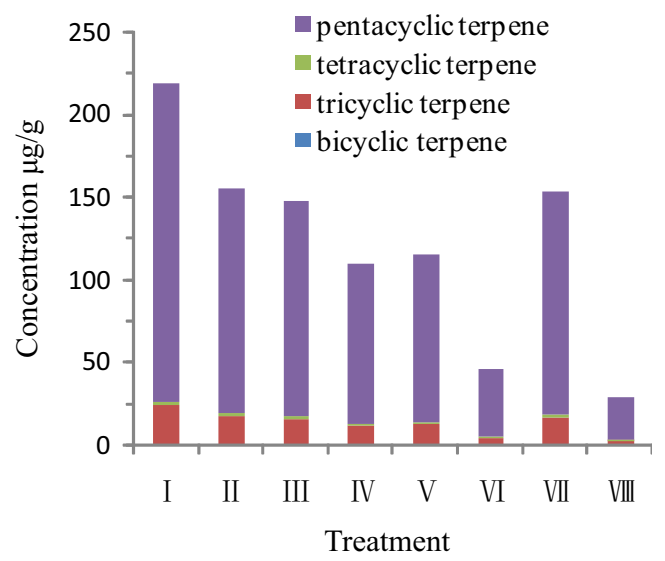

Fig. 3 Terpenoid content of residual oil in each treatment easily decomposed than $T_{s}$ and moretane, respectively. Steranes are important biomarkers in sedimentary deposits and crude oil. Steranes are derived from steroids, and they are relatively resistant to biodegradation in the natural process of diagenesis compared with $n$-alkanes and acyclic isoprenoids.

In each component of crude oil, $n$-alkanes are more biodegradable than isoalkanes (including $\mathrm{Pr}$ and $\mathrm{Ph}$ ) and polycyclic aromatic hydrocarbons (PAHs). Terpanes, steranes, triaromatic steranes, and other biomarkers are also resistant to biodegradation (Mcintyre et al. 2007). However, many studies have shown that chemical oxidation promotes chemolysis and the biodegradation of petroleum contaminants in soil (Lu et al. 2010a, b; Gong 2012; Xu et al. 2011). Xu et al. (2011) used a modified Fenton reaction to oxidize tankoil-contaminated soil, and the total petroleum hydrocarbons and the $\mathrm{C}_{10}-\mathrm{C}_{40}$ components were reduced by different degrees. Greater decomposition occurred in the $\mathrm{C}_{25}-\mathrm{C}_{40}$ molecular weight components. After 26 days of the chemical oxidation, the biodegradability of the petroleum hydrocarbon contaminants was increased by $20-30 \%$. The current experimental results indicated that the Fenton treatment (V) and the ultrasound-Fenton combined treatment (VI and VIII) could significantly remove various kinds of constituents, including $n$-alkanes $\left(\mathrm{C}_{\mathrm{n}} \mathrm{H}_{2 \mathrm{n}+2}, n<28\right)$, isoprenoids, polycyclic terpenes, and regular sterane.

Gong (2012) demonstrated that during the remediation of aged oil-contaminated soil using the Fenton reaction, in which $\mathrm{H}_{2} \mathrm{O}_{2}$ was catalyzed by an $\mathrm{Fe}^{3+}$-nitrilotriacetic acid complex, peanut shells and nutrients (C/N/P ratio of 100:10:5) could be added for biological processing. After 20 weeks of culture, the reduction of total petroleum hydrocarbons (TPHs) in soil was $55.1 \%$, and the reduction resulting from the Fenton oxidation-biological treatment was $88.9 \%$. This showed that the 
Table 3 Characteristics of the parameters of the saturated hydrocarbon biomarkers in each treatment

\begin{tabular}{lrrrrrrrrr}
\hline Parameters & \multicolumn{1}{l}{ Treatments } \\
\cline { 2 - 10 } & I & \multicolumn{1}{l}{ II } & \multicolumn{1}{l}{ III } & IV & V & VI & VII & VIII \\
\hline Pregnane index $^{\mathrm{a}}$ & 0.63 & 0.68 & 0.69 & 0.61 & 0.67 & 0.61 & 0.65 & 0.61 \\
Regular steranes/rearranged steranes & 17.09 & 17.71 & 17.71 & 17.26 & 17.73 & 15.70 & 16.83 & 15.50 \\
Regular steranes/hopane & 6.69 & 6.61 & 6.45 & 6.46 & 6.36 & 6.21 & 6.52 & 6.31 \\
Normoretane/moretane & 0.66 & 0.60 & 0.59 & 0.64 & 0.62 & 0.57 & 0.50 & 0.42 \\
Gammacerane index $^{\mathrm{b}}$ & 2.48 & 2.48 & 2.48 & 2.50 & 2.44 & 2.51 & 2.51 & 2.47 \\
$\mathrm{~T}_{\mathrm{m}} / \mathrm{T}_{\mathrm{s}}^{\mathrm{c}}$ & 2.75 & 2.85 & 2.81 & 2.84 & 2.71 & 2.76 & 2.63 & 2.63 \\
Hopane/moretane & 6.91 & 6.76 & 6.86 & 6.62 & 6.65 & 6.72 & 6.20 & 6.77 \\
Norhopane/hopane & 0.45 & 0.46 & 0.45 & 0.46 & 0.46 & 0.46 & 0.46 & 0.44 \\
Pregnane/homopregnane & 2.12 & 2.16 & 2.13 & 2.19 & 2.15 & 2.13 & 2.15 & 2.06 \\
Rearranged steranes/hopane & 0.39 & 0.37 & 0.36 & 0.36 & 0.36 & 0.42 & 0.37 & 0.38 \\
\hline
\end{tabular}

${ }^{\mathrm{a}}$ Pregnane index $=$ pregnanes $/ \Sigma \mathrm{C}_{29}$ regular steranes

${ }^{\mathrm{b}}$ Gammacerane index $=$ gammacerane $/ 17 \alpha(\mathrm{H}), 21 \beta(\mathrm{H})$-30-norhopane

${ }^{\mathrm{c}} \mathrm{T}_{\mathrm{m}}=17 \alpha(\mathrm{H})-22,29,30$ trinorhopane, $\mathrm{T}_{\mathrm{s}}=18 \alpha(\mathrm{H})-22,29,30$ trinorhopane. biodegradability of residual petroleum hydrocarbons in soil was improved by the Fenton oxidation process and was more beneficial to subsequent degradation by indigenous microorganisms.

\section{Effects of the ultrasound and Fenton treatments on the aromatic components}

The spectral characteristics of the aromatic hydrocarbon biomarkers and the ion fragment information from MS indicated that there were 175 PAHs. Many kinds of naphthalene compounds such as monomethyl naphthalene and dimethyl naphthalene could not be detected, which showed that the naphthalene compounds were easily volatilized. Except for the control and ultrasound-only treatments, all other treatments (Fenton treatment, Fenton-like treatment, ultrasound-Fenton treatment, ultrasound-Fenton-like treatment) significantly reduced the PAH concentrations (Fig. 4). Based on the PAH composition of the residual oil, triaromatic steranes and tricyclic

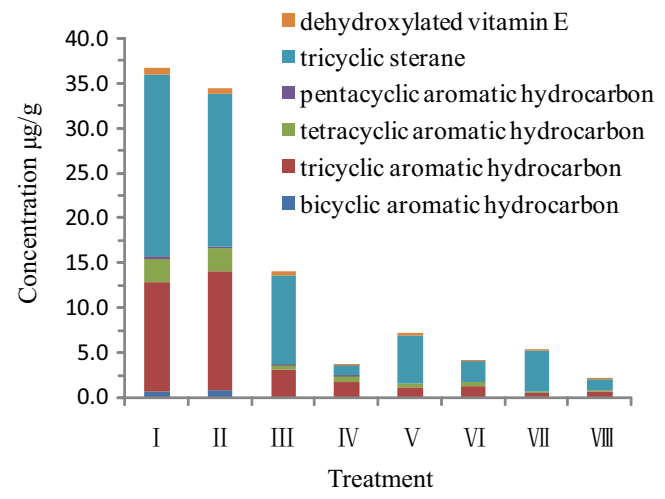

Fig. 4 PAHs content of residual oil in each treatment aromatic hydrocarbons accounted for the largest proportion, followed by tetracyclic aromatic hydrocarbons. Bicyclic aromatic hydrocarbons, pentacyclic aromatic hydrocarbons, and dehydroxylated vitamin $\mathrm{E}$ accounted for a relatively small proportion. The removal rates of PAHs in the Fenton and ultrasound-Fenton $\left(\mathrm{Fe}^{2+}\right.$ or $\left.\mathrm{Fe}^{3+}\right)$ treatments were higher and the concentrations of PAHs were reduced by 61.9 $94.2 \%$ compared with the control. The concentrations of PAHs following ultrasound-Fenton $\left(\mathrm{Fe}^{2+}\right.$ or $\left.\mathrm{Fe}^{3+}\right)$ treatments were $42.1-73.3 \%$ lower than that of the Fenton treatment alone. Ultrasonic treatment alone reduced the PAH concentration by $6.3 \%$ compared with the control. The six types of PAHs listed above could be ranked by ease of decomposition: Bicyclic aromatic hydrocarbons were the most easily decomposed, followed by tricyclic aromatic hydrocarbons, tetracyclic aromatic hydrocarbons, and pentacyclic aromatic hydrocarbons. Tricyclic steranes and dehydroxylated vitamin $\mathrm{E}$ are relatively stable and were not easily oxidized and decomposed. These results are consistent with the results of Huang et al. (2005) and Lemaire et al. (2013).

The degradation susceptibility of the PAHs appears to be related to their solubility, the number of the benzene ring, the types of substituents, the position of the substituents, and the properties of the heterocyclic atoms (Sun et al. 2014; Venny et al. 2012a; Coates et al. 1996). Low molecular weight PAHs (consisting of two to three aromatic rings) are relatively easy to degrade, while higher molecular weight PAHs (containing four or more aromatic rings) are more persistent. Naphthalene, fluorene, phenanthrene, anthracene, fluoranthene, and pyrene can be completely biodegraded in PAH-contaminated soil, and in an unpolluted agricultural soil, they were degraded within 4-50 days (Wang et al. 2010). With the exception of dibenzo(a,h)anthrancene, the other PAHs including 
benzo(a)anthracene, benzo(a)pyrene, benzo(b) fluoranthene, and benzo(k)fluoranthene were degraded to different degrees in both soils over a period of 170 days (Wang et al. 2010).

$\mathrm{Fe}^{3+}$ and organic chelating agents, such as catechol and gallic acid, were used to conduct a modified Fenton (MF) reaction, and a combination of MF and biodegradation led to more than $98 \%$ removal of the low molecular weight PAHs and more than $70 \%$ removal of the high molecular weight PAHs (Venny et al. 2012a). This effect can be attributed to the susceptibility of these compounds to reactions with hydroxyl radicals.

Four types of tricyclic aromatic hydrocarbons dibenzofuran, fluorene, dibenzothiophene, and phenanthrene were detected in the residual oil in each treatment, except for anthracene. Their concentrations were ranked (high to low) in the following order: phenanthrene $>$ dibenzothiophene $>$ fluorene $>$ dibenzofuran (Fig. 5). The concentrations of four types of tricyclic aromatic hydrocarbons were significantly reduced in all treatments except for the ultrasonic treatment (II). The ranking of the magnitude of the tricyclic aromatic hydrocarbons concentration reduction was dibenzofuran $>$ fluorene $>$ dibenzothiophene $>$ phenanthrene, which was the same as the degradation order of tricyclic aromatic hydrocarbons resulting from Fenton oxidation and ultrasound-Fenton oxidation. Dibenzofuran is susceptible to degradation, and dibenzothiophene and phenanthrene are relatively difficult to degrade. The ultrasound-only treatment seemed to promote the conversion of triaromatic steranes to tricyclic aromatic hydrocarbons (Figs. 3 and 4).

The effects of the position and number of substituents on the degradation of the phenanthrene derivatives were analyzed. The results showed that with the exception of the ultrasound treatment (II), all other treatments significantly reduced the concentrations of alkyl phenanthrene isomers compared with the control (Fig. 6), and the ranking of the magnitude of the concentration reduction was phenanthrene $>$ methylphenanthrene $>$ dimethyl phenanthrene, C-3 phenanthrene (meaning that three carbon atoms are replaced by a methyl or ethyl groups), trimethyl phenanthrene $>$ retene (1-methyl-

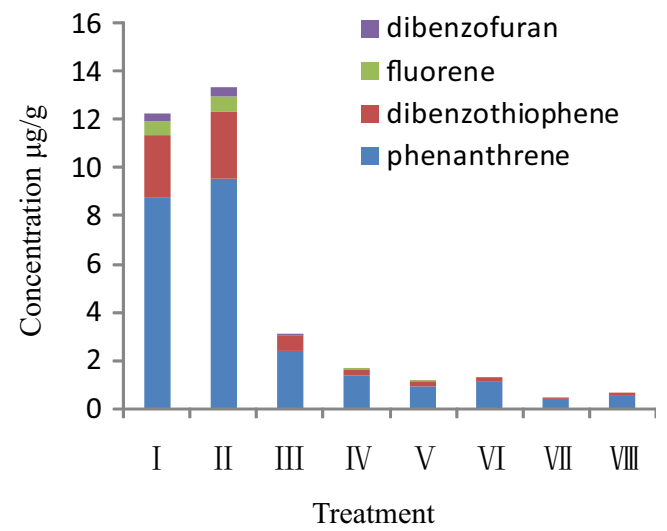

Fig. 5 Content of tricyclic aromatic hydrocarbons in residual oil in each treatment

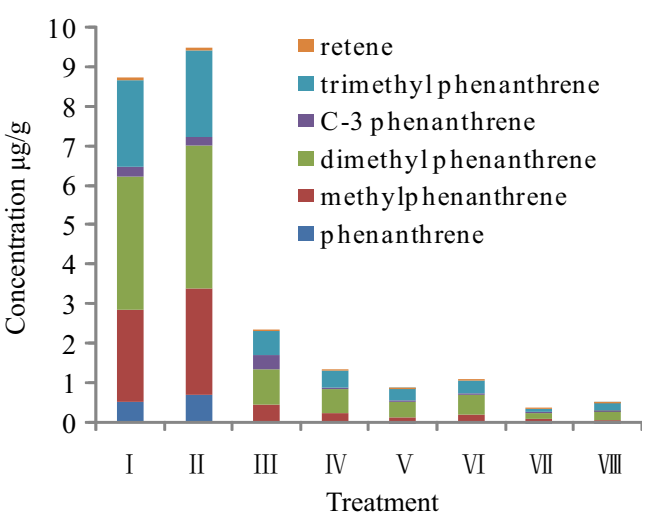

Fig. 6 Content of phenanthrene derivatives in residual oil in each treatment

7-isopropyl phenanthrene). These results indicated that phenanthrene degraded easily in the Fenton and ultrasound-Fenton treatments, followed by methylphenanthrene and multiple methyl-substituted phenanthrenes. This is consistent with the order of the microbial degradation of alkyl phenanthrenes. There is an apparent selectivity in the biodegradation of methylphenanthrene isomers, and 9-methyl-phenanthrene is the most resistant to biodegradation among the four methylphenanthrene isomers (Nadalig et al. 2000). Examining the chemistry of the compounds most resistant to biodegradation, various PAH parameters of residual oil were analyzed (Table 4). The use of the ultrasound or ultrasound-Fenton reaction treatments decreased the ratios of phenanthrene/ dibenzothiophene, benz(a)anthracene/(benz(a) anthracene + flexor), and C-3 phenanthrene/C-2 flexor. These treatments enhanced the relative decomposition of dibenzothiophene, benz(a) anthracene, and C-3 phenanthrene, while the other parameters showed no obvious trends.

\section{Conclusions}

Both the Fenton reaction combined with the $\mathrm{Fe}^{2+}$-oxalate complex and the Fenton reaction combined with ultrasonic treatment significantly improved the removal of residual oil from contaminated soil. Treatment with ultrasound alone or Fenton oxidation alone produced lower removal rates. There was a significant additive effect when the Fenton reaction was combined with the ultrasonic treatment.

When the $\mathrm{Fe}^{2+} / \mathrm{Fe}^{3+}$-oxalate complex Fenton reagent was combined with the ultrasonic process to treat crude-oilcontaminated soil, $n$-alkanes, isoprenoid hydrocarbons, and saturated aromatic hydrocarbons (containing polycyclic terpenoids) were removed in significant amounts compared with the control treatment. Therefore, the Fenton reaction or ultrasound-Fenton reaction can non-selectively remove multiple components of residual hydrocarbons. 
Table 4 Characteristics of PAHs parameters of residual oil in each treatment

\begin{tabular}{|c|c|c|c|c|c|c|c|c|}
\hline \multirow[t]{2}{*}{ Parameters } & \multicolumn{8}{|c|}{ Treatments } \\
\hline & I & II & III & IV & $\mathrm{V}$ & VI & VII & VIII \\
\hline Methylphenanthrene index $F 1^{\mathrm{a}}$ & 0.44 & 0.45 & 0.45 & 0.50 & 0.46 & 0.45 & 0.46 & 0.45 \\
\hline Methylphenanthrene index F2 ${ }^{\mathrm{b}}$ & 0.85 & 0.83 & 1.03 & 0.93 & 1.05 & 0.99 & 0.87 & 0.88 \\
\hline Methyldibenzothiophene index $\mathrm{MDBI}^{\mathrm{c}}$ & 0.49 & 0.49 & 0.54 & 0.46 & 0.44 & 0.46 & 0.41 & 0.41 \\
\hline Phenanthrene/dibenzothiophene & 10.47 & 10.13 & 24.19 & 7.71 & 13.73 & 6.79 & 12.92 & 2.90 \\
\hline Methylphenanthrene/methyldibenzothiophene & 5.59 & 5.50 & 7.09 & 7.63 & 10.50 & 12.67 & 7.01 & 7.33 \\
\hline Benz(a)anthracene/(benz(a)anthracene + flexor) & 0.04 & 0.04 & 0.06 & 0.06 & 0.05 & 0.03 & 0.14 & 0.07 \\
\hline C-3 phenanthrene/C-2 flexor $^{\mathrm{d}}$ & 0.23 & 0.24 & 0.44 & 0.23 & 0.54 & 0.37 & 0.77 & 0.39 \\
\hline
\end{tabular}

${ }^{\mathrm{a}}$ Methylphenanthrene index F1 = (3-MP + 2-MP)/(1-MP + 2-MP + 3-MP + 9-MP), MP represents methylphenanthrene

${ }^{\mathrm{b}}$ Methylphenanthrene Index F2 $=1.5 \times(3-\mathrm{MP}+2-\mathrm{MP}) /(\mathrm{P}+1-\mathrm{MP}+9-\mathrm{MP}), \mathrm{P}$ represents phenanthrene

${ }^{\mathrm{c}}$ Methyldibenzothiophene index MDBI = 4-MDBT/(DBT + 1-MDBT + 2-MDBT + 3-MDBT + 4-MDBT), DBT represents dibenzothiophene, MDBT represents methyldibenzothiophene

${ }^{\mathrm{d}} \mathrm{C}-2$ flexor represents two carbon atoms in flexor molecular structure are replaced by a methyl or ethyl groups

For saturated steroid hydrocarbons are not susceptible to biodegradation, the ultrasound-Fenton treatment can improve the degradation of pregnane, regular steranes, normoretanes, and other steroids compared with the ultrasound alone or Fenton reaction treatments.

For the Fenton oxidation and ultrasound-Fenton oxidation treatments, the degradation ranking (high to low) of the tricyclic aromatic hydrocarbons that account for a large proportion of PAHs was dibenzofuran $>$ fluorene $>$ dibenzothiophene $>$ phenanthrene. The ultrasonic treatment promoted the conversion of triaromatic hydrocarbons to steranes. The degradation of phenanthrene compounds was related to the position and number of substituents, and the degradation order of phenanthrene-derived hydrocarbons by the Fenton and ultrasound-Fenton treatments was phenanthrene $>$ methylphenanthrene $>$ dimethylphenanthrene, C-3 phenanthrene, trimethylphenanthrene $>$ retene.

Acknowledgments This study was funded by the National Natural Science Foundation of China (No: 41271482). We thank Cuishan Zhu at Yangtze University for sample analysis.

Open Access This article is distributed under the terms of the Creative Commons Attribution 4.0 International License (http://creativecommons.org/licenses/by/4.0/), which permits unrestricted use, distribution, and reproduction in any medium, provided you give appropriate credit to the original author(s) and the source, provide a link to the Creative Commons license, and indicate if changes were made.

\section{References}

Al-Mutairi N, Bufarsan A, Al-Rukaibi F (2008) Ecorisk evaluation and treatability potential of soils contaminated with petroleum hydrocarbon-based fuels. Chemosph 74(1):142-148
Bokare AD, Choi W (2014) Review of iron-free Fenton-like systems for activating $\mathrm{H}_{2} \mathrm{O}_{2}$ in advanced oxidation processes. J Hazard Mater 275:121-135

Chakma S, Moholkar VS (2011) Mechanistic features of ultrasonic desorption of aromatic pollutants. Chem Eng J 175:356-367

Coates JD, Anderson RT, Woodward JC, Phillips EJP, Lovley DR (1996) Anaerobic hydrocarbon degradation in petroleum contaminated harbor sediments under sulfate-reducing and artificially imposed ironreducing conditions. Environ Sci Technol 30:2764-2769

ElShafei GMS, Yehia FZ, Dimitry OIH, Badawi AM, Eshaq G (2014) Ultrasonic assisted-Fenton-like degradation of nitrobenzene at neutral $\mathrm{pH}$ using nanosized oxides of $\mathrm{Fe}$ and $\mathrm{Cu}$. Ultrason Sonochem 21:1358-1365

Goi A, Kulik N, Trapido M (2006) Combined chemical and biological treatment of oil contaminated soil. Chemosphere 63:1754-1763

Gong XB (2012) Remediation of weathered petroleum oil-contaminated soil using a combination of biostimulation and modified Fenton oxidation. Int Biodeterior Biodegrad 70:89-95

Huang KC, Zhao Z, Hoag GE, Dahmani A, Block PA (2005) Degradation of volatile organic compounds with thermally activated persulfate oxidation. Chemosphere 61(4):551-560

Jiang C, Gao Z, Qu HL, Li JW, Wang XX, Li P, Liu H (2013) A new insight into Fenton and Fenton-like processes for water treatment: part II Influence of organic compounds on $\mathrm{Fe}(\mathrm{III}) / \mathrm{Fe}(\mathrm{II})$ interconversion and the course of reactions. J Hazard Mater 250-251: $76-81$

Lemaire J, Buès M, Kabeche T, Hanna K, Simonnot MO (2013) Oxidant selection to treat an aged PAH contaminated soil by in situ chemical oxidation. J Environ Chem Eng 1:1261-1268

Lu M, Zhang Z, Qiao W, Guan Y, Xiao M, Peng C (2010a) Removal of residual contaminants in petroleum-contaminated soil by Fentonlike oxidation. J Hazard Mater 179(1-3):604-611

Lu M, Zhang Z, Qiao W, Wei X, Quan Y, Ma Q, Guan Y (2010b) Remediation of petroleum-contaminated soil after composting by sequential treatment with Fenton-like oxidation and biodegradation. Bioresour Technol 101(7):2106-2113

Mater L, Sperb RM, Madureira LAS, Rosin AP, Correa AXR, Radetski CM (2006) Proposal of a sequential treatment methodology for the safe reuse of oil sludge-contaminated soil. J Hazard Mater B 136: 967-971

Mcintyre CP, Harvey PM, Ferguson S, Wressnig AM, Snape I, George SC (2007) Determing the extent of weathering of spilled fuel in 
contaminated soil using the diastereomers of pristine and phytane. Org Geochem 38(12):2131-2134

Nadalig T, Raymond N, Gilewicz M, Budzinski H (2000) Development of a protocol to study aerobic bacterial degradation of polycyclic aromatic hydrocarbons: application to phenanthrenes. Polycycl Aromat Compd 18(2):177-192

Ning X, Chen H, Wu J, Wang Y, Liu J, Lin M (2014) Effects of ultrasound assisted Fenton treatment on textile dyeing sludge structure and dewaterability. Chem Eng J 242:102-108

Pignatello JJ, Oliveros E, MacKay A (2006) Advanced oxidation processes for organic contaminant destruction based on the Fenton reaction and related chemistry. Crit Rev Environ Sci Technol 36:1-84

Rastogi A, Al-Abed SR, Dionysiou DD (2009) Effect of inorganic, synthetic and naturally occurring chelating agents on Fe(II) mediated advanced oxidation of chlorophenols. Water Res 43:684-694

Siddique M, Farooq R, Price GJ (2014) Synergistic effects of combining ultrasound with the Fenton process in the degradation of Reactive Blue 19. Ultrason Sonochem 21:1206-1212

Sivasankar T, Moholkar VS (2009) Physical insights into the sonochemical degradation of re-calcitrant organic pollutants with cavitation bubble dynamics. Ultrason Sonochem 16:769-781

Souza BM, Dezotti MWC, Boaventura RAR, Vilar VJP (2014) Intensification of a solar photo-Fenton reaction at near neutral $\mathrm{pH}$ with ferrioxalate complexes: a case study on diclofenac removal from aqueous solutions. Chem Eng J 256:448-457

Sun GD, Jin JH, Xu Y, Zhong ZP, Liu Y, Liu ZP (2014) Isolation of a high molecular weight polycyclic aromatic hydrocarbon degrading strain and its enhancing the removal of HMW-PAHs from heavily contaminated soil. Int Biodeterior Biodegrad 90:23-28

Tsai TT, Kao CM (2009) Treatment of petroleum-hydrocarbon contaminated soils using hydrogen peroxide oxidation catalyzed by waste basic oxygen furnace slag. J Hazard Mater 170:466-472
Venny, Gan S, Ng HK (2012a) Modified Fenton oxidation of polycyclic aromatic hydrocarbon (PAH)-contaminated soils and the potential of bioremediation as post-treatment. Sci Total Environ 419:240-249

Venny, Gan S, Ng HK (2012b) Inorganic chelated modified-Fenton treatment of polycyclic aromatic hydrocarbon $(\mathrm{PAH})$ contaminated soils. Chem Eng J 180:1-8

Vicente F, Rosas JM, Santos A, Romero A (2011) Improvement soil remediation by using stabilizers and chelating agents in a Fentonlike process. Chem Eng J 172:689-697

Villalobos M, Avila-Forcada AP, Gutierrez-Ruiz ME (2008) An improved gravimetric method to determine total petroleum hydrocarbons in contaminated soils. Water Air Soil Pollut 194:151-161

Wang C, Wang F, Wang T, Bian Y, Yang X, Jiang X (2010) PAHs biodegradation potential of indigenous consortia from agricultural soil and contaminated soil in two-liquid-phase bioreactor (TLPB). J Hazard Mater 176:41-47

Watts RJ, Teel AL (2005) Chemistry of modified Fenton's reagent (catalyzed $\mathrm{H}_{2} \mathrm{O}_{2}$ propagations-CHP) for in situ soil and groundwater remediation. J Environ Eng 131:612-622

Xu J, Xin L, Huang T, Chang K (2011) Enhanced bioremediation of oil contaminated soil by graded modified Fenton oxidation. J Environ Sci 23(11):1873-1879

Xue X, Hanna K, Despas C, Wu F, Deng N (2009) Effect of chelating agent on the oxidation rate of $\mathrm{PCP}$ in the magnetite $/ \mathrm{H}_{2} \mathrm{O}_{2}$ system at neutral pH. J Mol Catal A Chem 311:29-35

Zhang J, Li J, Thring R, Liu L (2013) Application of ultrasound and Fenton's reaction process for the treatment of oily sludge. Proced Environ Sci 18:686-693

Zhou T, Lim TT, Wu X (2011) Sonophotolytic degradation of azo dye reactive black 5 in an ultrasound/UV/ferric system and the roles of different organic ligands. Water Res 45(9):2915-2924 